\title{
Low Serum Vitamin D Is Associated with Anti-Thyroid-Globulin Antibody in Female Individuals
}

\author{
Xinling Wang, Jazyra Zynat, Yanying Guo, Reziwan Osiman, Aihemaitjan Tuhuti, \\ Hongli Zhao, Munira Abdunaimu, Huili Wang, Xiaoping Jin, and Shuqing Xing \\ Department of Endocrinology, People’s Hospital of Xinjiang Uyghur Autonomous Region, Urumqi 830000, China \\ Correspondence should be addressed to Yanying Guo; guozeyang@126.com
}

Received 13 July 2015; Revised 16 September 2015; Accepted 30 September 2015

Academic Editor: Salvatore Minisola

Copyright (c) 2015 Xinling Wang et al. This is an open access article distributed under the Creative Commons Attribution License, which permits unrestricted use, distribution, and reproduction in any medium, provided the original work is properly cited.

\begin{abstract}
Objectives. Some evidence has pointed out that vitamin D plays a significant role in reducing the incidence of autoimmune diseases, especially autoimmune thyroid diseases. The authors aimed to examine the relationship between circulating 25-hydroxyvitamin D and thyroid autoantibody in a population-based health survey of Xinjiang Chinese population. Subjects and Methods. A total of 1714 Chinese adults were analyzed. $25(\mathrm{OH}) \mathrm{D}$, anti-thyroid antibodies, and thyroid function were measured. Results. The prevalence of vitamin D insufficiency was $28.3 \%$ in Hans and 9.3\% in Uyghurs, and the prevalence of vitamin D deficiency was $61.6 \%$ in Hans and $87.6 \%$ in Uyghurs. Overall prevalence of TgAb positivity was $6.2 \%$ ( $0.9 \%$ males; $5.3 \%$ females). In female subjects, mean serum $25(\mathrm{OH}) \mathrm{D}$ levels were significantly lower in Hans and Uyghurs compared with males, and the difference was statistically significant. Importantly, after adjusting for age and ethnicity, a negative correlation $(r=-0.121, P=0.014)$ was recognized between $25(\mathrm{OH}) \mathrm{D}$ and TgAb levels only in female subjects. Conclusion. Vitamin D insufficiency and deficiency are prevalent among Chinese adults. Low serum 25(OH)D is related to the presence of TgAb in females. The causal effect of low vitamin D level on thyroid autoimmunity should be studied further more.
\end{abstract}

\section{Introduction}

Vitamin D insufficiency and/or deficiency are becoming a global health problem. Its role as an immune modulator has been recently emphasized. Many studies provide evidence pointing to a clear role of vitamin $\mathrm{D}$ in the pathogenesis of autoimmune diseases, especially autoimmune thyroid diseases (AITDs), as vitamin D deficiency is linked with high levels of anti-thyroid antibodies, abnormal thyroid function, increased thyroid volume, and increased TSH levels [1-4]. Nevertheless, at the present time vitamin D levels above $30 \mathrm{ng} / \mathrm{mL}$ are considered sufficient and confer protection from bone disease, whereas lower levels induce elevation of parathyroid hormone and are associated with other hazardous systemic effects [5]. However, it is unclear whether low vitamin D levels are closely associated with the development of autoimmune thyroid disease. Some case-control studies have suggested that lower serum vitamin $\mathrm{D}$ levels or a higher prevalence of vitamin D insufficiency existed in patients with AITDs compared with that in healthy controls $[1,2,6,7]$.
However, another study reported no significant association between serum vitamin $\mathrm{D}$ levels and thyroid autoimmunity [4]. Thus, we aim to estimate the associations between vitamin D deficiency and/or insufficiency and autoimmune thyroid diseases, especially to clarify the relationship between vitamin $\mathrm{D}$ and serum thyroid autoantibody, in a relative rather than quantitative manner by comparing levels of vitamin $\mathrm{D}$ in a Chinese population.

\section{Subjects and Methods}

2.1. Study Population. From May to June 2013 this study was performed in Ürümqi of Xinjiang province. Adults aged 16 years and above who were Chinese citizens and lived in current residence for 3 years or longer were selected and invited into our study. Those with severe communication problems and acute illness and unwilling to participate were excluded from the study. A total of 2253 people participated in this investigation (Figure 1). We excluded participants who 
TABle 1: Clinical characteristics for the participants.

\begin{tabular}{lcccc}
\hline & Ethnicity & Male & Female & $P$ value \\
\hline \multirow{2}{*}{ Age } & Han & $45.05 \pm 17.47$ & $49.99 \pm 14.11$ & 0.000 \\
& Uyghur & $48.51 \pm 14.58$ & $42.04 \pm 11.63$ & 0.000 \\
\hline \multirow{2}{*}{$25(\mathrm{OH}) \mathrm{D}(\mathrm{ng} / \mathrm{mL})$} & Han & $19.86 \pm 7.18$ & $19.18 \pm 8.88$ & $11.67 \pm 7.28^{\mathrm{a}}$ \\
& Uyghur & $16.04 \pm 6.01^{\mathrm{a}}$ & $2.76(1.83-4.16)$ & 0.000 \\
\hline \multirow{2}{*}{$\mathrm{TSH}(\mathrm{IU} / \mathrm{mL})$} & Han & $2.18(1.51-3.20)$ & $2.32(1.47-3.97)^{\mathrm{a}}$ & 0.000 \\
& Uyghur & $1.89(1.33-2.82)^{\mathrm{a}}$ & 0.007 \\
\hline \multirow{2}{*}{$\mathrm{TPOAb}(\mathrm{IU} / \mathrm{mL})$} & Han & $24.21(19.75-30.42)$ & $27.54(22.96-36.97)$ & 0.000 \\
& Uyghur & $25(19.57-33.14)^{\mathrm{a}}$ & $28.28(22.15-40.89)^{\mathrm{a}}$ & 0.000 \\
\hline \multirow{2}{*}{$\mathrm{TgAb}(\mathrm{IU} / \mathrm{mL})$} & Han & $27.30(24.50-31.48)$ & $30.24(26.11-70.58)$ & $32.48(27.43-103.4)^{\mathrm{a}}$ \\
& Uyghur & $28.57(24.48-32.65)^{\mathrm{a}}$ & 0.000 \\
\hline
\end{tabular}

${ }^{\text {a }}$ Significantly different from Uyghurs $(P \leq 0.001)$.

TSH: thyroid-stimulating hormone; 25(OH)D: serum 25-hydroxyvitamin D; TPOAb: anti-thyroid peroxidase antibody; TgAb: anti-thyroid-globulin antibody.

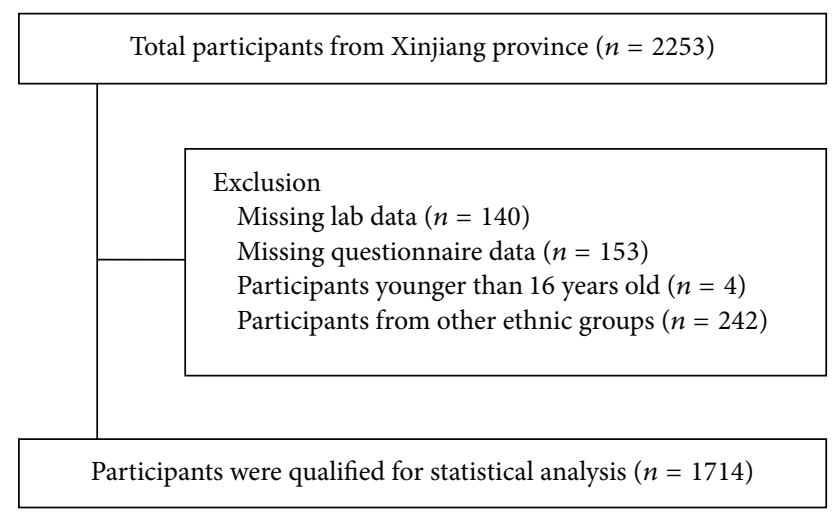

FIGURE 1: Flow diagram of participant enrollment in our study.

had missing lab results $(n=140)$ and questionnaire data $(n=153)$ and were younger than 16 years old $(n=4)$ and other ethnic groups $(n=242)$. Finally, 1714 subjects were enrolled, including Han and Uyghur. The study protocol was approved by the Ethics Committee of People's Hospital of Xinjiang Uyghur Autonomous Region. Informed consent was obtained from all subjects before data collection.

In our study site, all the data collection was performed by the same staff group from Department of Endocrinology in People's Hospital of Xinjiang Uyghur Autonomous Region. They were trained according to a standard protocol that made them familiar with the specific tools and methods used. Venous blood samples were drawn after an overnight fast of at least $8 \mathrm{~h}$ and centrifuged on the spot after collection. Blood samples were collected and stored at $-80^{\circ} \mathrm{C}$.

2.2. Laboratory Tests. Serum $25(\mathrm{OH}) \mathrm{D}$ levels and thyroid parameters, serum TSH, and the levels of TgAb and TPOAb were measured with a Roche electrochemiluminometric analyzer (E601), with an interassay variance of $<10 \%$. It is generally agreed that serum $25(\mathrm{OH}) \mathrm{D}$ levels of 20 to $30 \mathrm{ng} / \mathrm{mL}$ should be considered as representative of vitamin $\mathrm{D}$ insufficiency, whereas serum $25(\mathrm{OH}) \mathrm{D}$ levels of $<20 \mathrm{ng} / \mathrm{mL}$ should be considered as an indicative of vitamin D deficiency [8].
Serum TPOAb of $>35 \mathrm{IU} / \mathrm{mL}$ and/or TgAb of $>116 \mathrm{IU} / \mathrm{mL}$ were considered autoantibody positivity (Roche).

2.3. Statistical Analysis. Continuous variables are presented as means \pm standard deviation for continuous normally distributed variables and median (interquartile range) for the nonnormally distributed variables. Student's $t$-test and Mann-Whitney $U$ test were used for comparison of mean values between groups. Linear regression analysis was used to examine the relationship between log-transformed $\mathrm{TgAb} / \mathrm{TPOAb}$ titer and age, ethnicity, $25(\mathrm{OH}) \mathrm{D}$, and other biochemical variables. Multivariate regression analysis was performed to identify the predictive variables. All calculations were performed using SPSS 19.0 for Windows (Chicago, IL, USA). A probability $(P)$ value of $<0.05$ was considered statistically significant for all tests.

\section{Results}

A total of 1,714 subjects ( 969 Han and 745 Uyghur) including 1,197 females (652 Han and 545 Uyghur) and 517 males (317 Han and 200 Uyghur) were enrolled in this study. The mean level of total serum $25(\mathrm{OH}) \mathrm{D}$ was $16.55 \pm 8.53 \mathrm{ng} / \mathrm{mL}$. Vitamin D deficiency and insufficiency were noted in 1250 (72.9\%) and $344(20.1 \%)$ subjects, respectively.

3.1. Clinical and Laboratory Characteristics. Females had higher serum TSH levels and TPOAb and TgAb titres but lower serum 25(OH)D levels than males $(P<0.05)$ (Table 1$)$. Ethnic subgroup studies showed that Uyghurs had higher TPOAb and TgAb titres but lower serum TSH and 25(OH)D levels compared to Hans $(P \leq 0.001)$. Han subjects were significantly older than Uyghurs (48.34 \pm 15.46 versus $43.78 \pm$ 12.81 years, $P<0.01)$. Vitamin D insufficiency was noted in 28.3\% of Han and 9.3\% of Uyghur residents and vitamin D deficiency was seen in $61.6 \%$ of Hans versus $87.6 \%$ of Uyghurs. As shown in Figure 2, Uyghurs had a lower mean 25(OH)D level compared to Hans $(19.40 \pm 8.37$ versus $12.84 \pm 7.23$, $P<0.001)$. In the ethnic Han subgroup, females had a lower mean $25(\mathrm{OH}) \mathrm{D}$ level compared to males $(19.18 \pm 8.88$ versus $19.86 \pm 7.18 \mathrm{ng} / \mathrm{mL}, P=0.002)$; similarly Uyghur females had 
TABLE 2: Comparison of clinical and laboratory characteristics based on the positivity of serum antibodies.

\begin{tabular}{lccc}
\hline & TPOAb $(+)$ & TgAb $(+)$ & TPOAb $(+) \operatorname{TgAb}(+)$ \\
\hline Male/female & $64 / 176$ & $15 / 91$ & $28 / 181$ \\
Han (\%) & $117(48.8 \%)$ & $48(45.3 \%)^{\mathrm{a}}$ & $120(57.4 \%)$ \\
Uyghur (\%) & $123(51.2 \%)$ & $58(54.7 \%)$ & $89(42.6 \%)$ \\
Age & $47.0 \pm 14.27$ & $47.5 \pm 13.39$ & $46.06 \pm 13.06$ \\
TSH (IU/mL) & $2.38(1.46-3.81)$ & $2.87(1.60-4.14)$ & $3.63(2.18-6.43)^{\mathrm{b}}$ \\
$25(\mathrm{OH}) \mathrm{D}(\mathrm{ng} / \mathrm{mL})$ & $15.44(10.9-21.97)$ & $13.61(10.05-18.47)^{\mathrm{b}}$ & $15.03(11.62-20.12)$ \\
\hline
\end{tabular}

${ }^{a}$ Significantly different from Uyghurs $(P<0.05) ;{ }^{b}$ significantly different from the other two groups $(P<0.01)$.

TSH: thyroid-stimulating hormone; 25(OH)D: serum 25-hydroxyvitamin D; TPOAb: anti-thyroid peroxidase antibody; TgAb: anti-thyroid-globulin antibody.

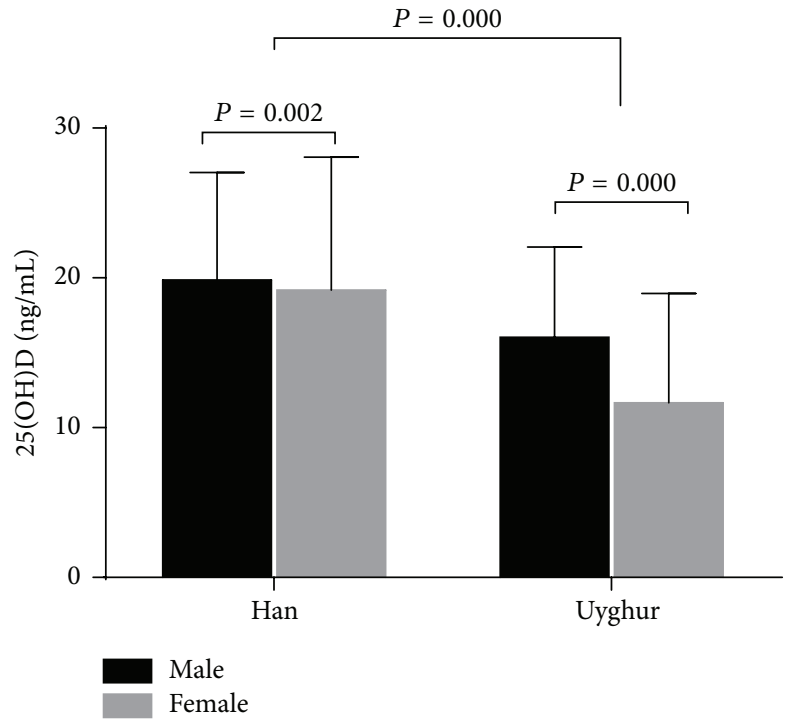

Figure 2: Serum levels of serum 25(OH)D in the study subjects according to the gender and ethnicity.

lower $25(\mathrm{OH}) \mathrm{D}$ levels than Uyghur males $(11.67 \pm 7.28$ versus $16.04 \pm 6.01 \mathrm{ng} / \mathrm{mL}, P<0.001)$.

3.2. Clinical and Laboratory Characteristics of Positive Serum Thyroid Antibodies. In the present study, 240 (14.0\%) subjects were positive for serum TPOAb and a total of $106(6.2 \%)$ subjects were positive for serum $\mathrm{TgAb}$, of which 209 (12.2\%) were positive for both serum TPOAb and serum TgAb. There were a significant high proportion of females compared to males in $\mathrm{TPO}(+), \operatorname{Tg}(+)$, and $\mathrm{TPO}(+) \mathrm{Tg}(+)$ groups $(73.3 \%$ versus $26.7 \%, P=0.203 ; 85.8 \%$ versus $14.2 \%, P<0.001$; $86.6 \%$ versus $13.4 \%, P<0.001$; resp.), while the proportion of Uyghurs was higher as compared to Hans $(P<0.05)$ only in the $\mathrm{Tg}(+)$ group but not in the $\mathrm{TPO}(+)$ and $\mathrm{TPO}(+) \mathrm{Tg}(+)$ groups. $\mathrm{TgAb}(+)$ group had a lower mean $25(\mathrm{OH}) \mathrm{D}$ level compared to the $\mathrm{TgAb}(-)$ group $(P<0.01)$. The prevalence of vitamin $\mathrm{D}$ deficiency in TgAb positive subjects was higher than that observed in TgAb negative subjects, while no statistical difference was found $(78.3 \%$ versus $72.6 \%, P=$ 0.199). The serum $\mathrm{TSH}$ levels in the $\mathrm{TPO}(+) \mathrm{Tg}(+)$ group
TABLE 3: Linear regression analysis with serum $\mathrm{TgAb}$ as a dependent variable.

\begin{tabular}{lcccc}
\hline & \multicolumn{2}{c}{ Male } & \multicolumn{2}{c}{ Female } \\
& $\beta$ & $P$ value & $\beta$ & $P$ value \\
\hline Age & -0.055 & 0.974 & 0.014 & 0.907 \\
Ethnicity & -0.006 & 0.995 & 0.003 & 0.739 \\
25(OH)D & -0.036 & 0.987 & -0.121 & 0.014 \\
TSH & 0.003 & 0.985 & 0.072 & 0.009 \\
TPOAb & 0.740 & 0.000 & 0.767 & 0.000 \\
\hline
\end{tabular}

were significantly higher than those in the $\mathrm{TPO}(+)$ group and $\operatorname{Tg}(+)$ group $(P<0.01)$. However, there was no significant difference between $\mathrm{TPO}(+)$ group and $\mathrm{Tg}(+)$ group (Table 2 ).

3.3. Relationship between Serum 25(OH)D Levels and AntiThyroid Antibodies. To account for the probable interaction between vitamin D status and anti-thyroid antibody level, further analyses were performed according to gender differences. It was found that higher $\mathrm{TgAb}$ titres were associated with lower 25(OH)D levels independent of age, ethnicity, and TSH levels in females (beta $=-0.121, P=0.014$, Table 3 ) but not in males. Linear regression analysis showed a weak relationship between TPOAb titres and serum 25(OH)D levels independent of age, ethnicity, and TSH levels (males, beta $=0.005, P=0.002$; females, beta $=0.006, P=0.000$, Table 4). Age, TSH, and thyroid-globulin antibody titres, but not $25(\mathrm{OH}) \mathrm{D}$ or ethnicity, were associated with TPOAb titres in men and women.

Given the findings of lower serum 25(OH)D levels in female subjects in the $\operatorname{TgAb}(+)$ group, we evaluated the adjusted odds ratios (ORs) for women using multivariate logistic regression model. The multivariate analysis using logistic regression revealed that $25(\mathrm{OH}) \mathrm{D}$ levels were an independent determinant of the presence of TgAb (odds ratio: $1.156,95 \%$ confidence interval: $1.004-1.331, P=0.043$; see Table 5) after adjusting for age, gender, and ethnicity. In this analysis, gender, ethnicity, and TSH showed a significant association with $\mathrm{TgAb}$ positivity. However, age had no significant association. 
TABLE 4: Linear regression analysis with serum TPOAb as a dependent variable.

\begin{tabular}{lcccc}
\hline & \multicolumn{2}{c}{ Male } & \multicolumn{2}{c}{ Female } \\
& $\beta$ & $P$ value & $\beta$ & $P$ value \\
\hline Age & 0.002 & 0.000 & -0.002 & 0.011 \\
Ethnicity & 0.063 & 0.912 & 0.048 & 0.724 \\
25(OH)D & 0.005 & 0.002 & 0.006 & 0.000 \\
TSH & 0.017 & 0.000 & 0.013 & 0.000 \\
TgAb & 0.548 & 0.000 & 0.507 & 0.000 \\
\hline
\end{tabular}

TABLE 5: Determinants of positive serum thyroglobulin antibody.

\begin{tabular}{lcc}
\hline & \multicolumn{2}{c}{ TgAb } \\
& Adjusted OR $(95 \% \mathrm{CI})$ & $P$ value \\
\hline Age & $0.999(0.990-1.009)$ & 0.855 \\
Gender & $3.157(2.230-4.469)$ & 0.000 \\
Ethnicity & $1.335(1.002-1.778)$ & 0.048 \\
$25(\mathrm{OH}) \mathrm{D}$ & $1.156(1.004-1.331)$ & 0.043 \\
TSH & $1.380(1.192-1.597)$ & 0.000 \\
\hline
\end{tabular}

\section{Discussion}

In the current study, we found that a low circulating $25(\mathrm{OH}) \mathrm{D}$ level was significantly associated with a higher risk of prevalent AITDs in females. To the best of our knowledge, this is the first study to investigate the association between circulating $25(\mathrm{OH}) \mathrm{D}$ and anti-thyroid antibodies in community based men and women from Xinjiang province of China.

According to our study performed, the mean serum vitamin D level in the Xinjiang population is $16.55 \pm 8.53 \mathrm{ng} / \mathrm{mL}$, and the prevalence of vitamin D deficiency is $72.9 \%$. This prevalence is remarkably high in the Uyghur population, especially in Uyghur females compared to males. Wearing covered clothing was reported to be associated with lower $25(\mathrm{OH}) \mathrm{D}$ levels [9]. The fact that vitamin $\mathrm{D}$ deficiency is predominantly found in Uyghur females signifies a certain association between these two conditions; it seems that the lower $25(\mathrm{OH}) \mathrm{D}$ level in Uyghurs is due to headscarves and clothing that covers the neck, arms, and legs. In contrast, Han populations are more mindful of their health and often exercise outdoors before and after work and with ordinary clothing, thereby increasing their sunshine exposure.

Lower vitamin D levels have been found in several autoimmune diseases, such as rheumatoid arthritis, systemic lupus erythematosus, systemic sclerosis, type 1 diabetes mellitus, multiple sclerosis, inflammatory bowel diseases, autoimmune thyroid diseases (i.e., Hashimoto's thyroiditis and Graves' disease), and autoimmune gastritis [10]. The mechanisms underlying the link between vitD and autoimmunity are not completely understood but probably are associated with its anti-inflammatory and immunomodulatory functions, as well as the presence of VDRs on most immune cells $[10,11]$. AITDs are multifactorial diseases in which autoimmunity plays a fundamental role with infiltration of the gland by $\mathrm{T}$ - and B-cells and production of specific autoantibodies, reactive to thyroid antigens [antithyroglobulin, anti-thyroid peroxidase (TPOAb), and anti-TSH receptor (TRAb)] [12]. Kivity et al. [1] reported, for the first time, a link between vitamin D deficiency and the presence of antithyroid antibodies. In recent years, evidence has emerged pointing to an involvement of vitamin $\mathrm{D}$ in the development of autoimmune thyroid disease [13]. The immune modulator properties of vitamin $\mathrm{D}$ are ascribed to its effect on cells of the innate and adaptive systems, including macrophages, dendritic cells, and T and B lymphocytes, all of which harbor VDR [11]. Recently, several genetic studies have demonstrated an association between thyroid autoimmunity susceptibility and gene polymorphisms of numerous proteins and enzymes that are associated with vitD functions, including VDR, DBP, CYP27B1, and CYP2R1 $[11,12,14]$. Activated vitamin D modulates autoimmune reactions by regulating $\mathrm{T}$ lymphocytes to inhibit both the production and activity of cytokines [15]. Vitamin D directly regulates $\mathrm{T}$ lymphocyte functions by inhibiting the proliferation of Thl cells and increasing the number of Th2 cells [16]. Vitamin D also suppresses the production of IL-2, IL-5, IFN-c, and TNF-a and increases the production of IL- 4 and transforming growth factor in Th2 cells [17]. There are no further experimental studies to reveal whether there is a casual relationship and what are the mechanisms between low serum vitamin D and anti-thyroid antibody presence. Hence, from the results of our study, we supposed that vitamin D may enhance the responsiveness in thyroid autoimmune reaction which induced $\mathrm{TgAb}$ secretion of thyrocytes.

In the present study, the prevalence of vitamin $\mathrm{D}$ deficiency $(78.3 \%)$ and insufficiency $(20 \%)$ is higher in TgAb positive subjects. In addition, we explored the probable interaction between vitamin D status and thyroid-globulin antibodies in female Xinjiang Chinese population. Similar to the study in other populations, it has been observed that women have higher serum antithyroglobulin antibody (TgAb) levels but lower serum 25(OH)D levels than men [3]. It is reported that vitamin D deficiency is more closely related to anti-thyroid antibody titer rather than thyroid function itself in humans [18]. Our study not only supports the existing argument on the association between vitamin D and AITDs but also further solidifies the association by revealing that $25(\mathrm{OH}) \mathrm{D}$ has a statistical correlation with TgAb presence.

Our current results suggest a possible crosstalk between vitamin D and X chromosome in the development of AITDs. The association of lower vitamin $\mathrm{D}$ levels with the higher prevalence of $\mathrm{TgAb}$ positivity was found to be significant only in women and not in men, which is likely to more accurately reflect the mean reference value of serum $25(\mathrm{OH}) \mathrm{D}$ and the relationship with $\mathrm{TgAb}$. AITDs have a female: male ratio of approximately $9: 1$ [19]. There is also some studies that provide strong evidence for female predominance and $\mathrm{X}$ chromosome involvement in AITDs, such as the finding that the $\mathrm{X}$ chromosome contains a considerable number of sex and immune-related genes that are essential in determining sex hormone levels and more importantly in immune tolerance, such as AR, IL-2 receptor gamma chain, CD40 ligand, and 
FOXP3 [20-22]. An alternative explanation has been recently proposed, that is, an enhanced skewed XCI in peripheral blood cells of female patients with autoimmune diseases [23-26]. Results from our study showed a significant high proportion of women in $\mathrm{Tg}(+)$ group, which is consistent with previous studies, making better understanding of AITDs occurrence risks from the perspective of sex determination genetics in females compared to males. The $\mathrm{X}$ chromosome has been a recurrently suspicious contributor to disease genetics, and many reports provide strong evidence that the prevalence of vitamin D deficiency or insufficiency was more severe in female individuals. Further clinical and experimental investigations of the effect of vitamin $\mathrm{D}$ supplementation on thyroid antibodies, particularly in female individuals, are needed to elucidate an effect of vitamin $\mathrm{D}$ on either the thyrocytes or the thyroid follicular epithelium and genetic differences that might provide insight into this relationship.

Most of the studies supported the inverse relation between low levels of 25(OH)D and autoimmune disease [1012]. Interestingly, in our study multivariate logistic regression analysis revealed that $25(\mathrm{OH}) \mathrm{D}$ was an independent risk factor of TgAb. We suppose that this result of the study indicated that both low and high levels of vitamin D may result in an increased prevalence of autoimmune thyroid diseases. Some studies have investigated the association between mortality and higher levels of $25(\mathrm{OH}) \mathrm{D}$ and found both high and low levels of $25(\mathrm{OH}) \mathrm{D}$ were associated with increased risk of overall mortality $[27,28]$. Durup et al. suggested a Ushaped relationship between serum $25(\mathrm{OH}) \mathrm{D}$ concentration and the frequency of certain pathologies [29]. Unfortunately, the appropriate range for vitamin $\mathrm{D}$ that will be safe and sufficient to modulate immunological homeostasis is yet to be determined.

It is generally agreed that high serum $25(\mathrm{OH}) \mathrm{D}$ levels are associated with low circulating TSH. Recently, populationbased studies have reported that high vitamin $\mathrm{D}$ status in younger individuals and middle-aged and elderly males is associated with low circulating thyroid-stimulating hormone (TSH) $[3,30]$. However, our study did not find a link between vitamin $\mathrm{D}$ status and thyrotropin after controlling for age, gender, ethnicity, and thyroid autoantibody. The lack of statistical significance may be due to the relatively small number of subjects, especially after subgroup analysis in different ethnics or genders.

Our study is limited by the fact that we did not record several factors affecting sun exposure, such as outdoor activity, difference in the use of sunscreens, and vacation activities. In our study, serum $25(\mathrm{OH}) \mathrm{D}$ was measured at the end of spring season in the Xinjiang region of China; the average amount of sunshine for May and June was up to 13-14 hours. However, our findings strongly suggest that we likely underestimate vitamin $\mathrm{D}$ deficiency in the population. Another limitation is the lack of information on differences in socioeconomic status between Hans and Uyghurs in this cohort. Besides, because of the cross-sectional nature of the present study, the causative effect of vitamin D on serum anti-thyroid-globulin antibody titres could not be readily determined.

\section{Conclusion}

Vitamin D insufficiency or deficiency is common among Chinese adults. 25(OH)D status was much worse among Uyghur (especially in females) populations, the prevalence of vitamin $\mathrm{D}$ deficiency and insufficiency was higher in $\mathrm{TgAb}$ positive individuals, and low serum $25(\mathrm{OH}) \mathrm{D}$ was associated with $\mathrm{TgAb}$ presence only in female subjects. Taken together, these data suggest a pathogenic relationship between vitamin D status and AITDs. Future studies are warranted to clarify the potential contribution of the low serum vitamin $\mathrm{D}$ to the development of autoimmune thyroid diseases.

\section{Conflict of Interests}

The authors declare that they have no conflict of interests regarding the publication of this paper.

\section{Acknowledgments}

The authors thank all the participants in this study. This work was supported by grants from (1) the National Natural Science Foundation of China (81260127) and (2) major project of Science and Technology Commission of Tianshan region of Ürümqi municipality (20120101).

\section{References}

[1] S. Kivity, N. Agmon-Levin, M. Zisappl et al., "Vitamin D and autoimmune thyroid diseases," Cellular and Molecular Immunology, vol. 8, no. 3, pp. 243-247, 2011.

[2] N. C. Bozkurt, B. Karbek, B. Ucan et al., "The association between severity of vitamin D deficiency and Hashimoto's thyroiditis," Endocrine Practice, vol. 19, no. 3, pp. 479-484, 2013.

[3] L.-O. Chailurkit, W. Aekplakorn, and B. Ongphiphadhanakul, "High vitamin D status in younger individuals is associated with low circulating thyrotropin," Thyroid, vol. 23, no. 1, pp. 25-30, 2013.

[4] R. Goswami, R. K. Marwaha, N. Gupta et al., "Prevalence of vitamin $\mathrm{D}$ deficiency and its relationship with thyroid autoimmunity in Asian Indians: a community-based survey," British Journal of Nutrition, vol. 102, no. 3, pp. 382-386, 2009.

[5] C. Gómez-Alonso, M. L. Naves-Díaz, J. L. Fernández-Martín, J. B. Díaz-López, M. T. Fernández-Coto, and J. B. CannataAndía, "Vitamin D status and secondary hyperparathyroidism: the importance of 25-hydroxyvitamin D cut-off levels," Kidney International, Supplement, vol. 63, no. 85, pp. S44-S48, 2003.

[6] M. Rotondi and L. Chiovato, "Vitamin D deficiency in patients with Graves' disease: probably something more than a casual association," Endocrine, vol. 43, no. 1, pp. 3-5, 2013.

[7] T. Yasuda, Y. Okamoto, N. Hamada et al., "Serum vitamin D levels are decreased and associated with thyroid volume in female patients with newly onset Graves' disease," Endocrine, vol. 42, no. 3, pp. 739-741, 2012.

[8] M.-C. Chapuy, P. Preziosi, M. Maamer et al., "Prevalence of vitamin D insufficiency in an adult normal population," Osteoporosis International, vol. 7, no. 5, pp. 439-443, 1997.

[9] J. Farahati, J. Nagarajah, E. Gilman et al., "Ethnicity, clothing style, and body mass index are significant predictors of vitamin 
D insufficiency in Germany," Endocrine Practice, vol. 21, no. 2, pp. 122-127, 2015.

[10] N. Agmon-Levin, E. Theodor, R. M. Segal, and Y. Shoenfeld, "Vitamin D in systemic and organ-specific autoimmune diseases," Clinical Reviews in Allergy and Immunology, vol. 45, no. 2, pp. 256-266, 2013.

[11] E. Delvin, J.-C. Souberbielle, J.-P. Viard, and B. Salle, "Role of vitamin D in acquired immune and autoimmune diseases," Critical Reviews in Clinical Laboratory Sciences, vol. 51, no. 4, pp. 232-247, 2014.

[12] F. D’Aurizio, D. Villalta, P. Metus, P. Doretto, and R. Tozzoli, "Is vitamin D a player or not in the pathophysiology of autoimmune thyroid diseases?" Autoimmunity Reviews, vol. 14, no. 5, pp. 363-369, 2015.

[13] D. Y. Shin, K. J. Kim, D. Kim, S. Hwang, and E. J. Lee, "Low serum vitamin $\mathrm{D}$ is associated with anti-thyroid peroxidase antibody in autoimmune thyroiditis," Yonsei Medical Journal, vol. 55, no. 2, pp. 476-481, 2014.

[14] G. Muscogiuri, J. Mitri, C. Mathieu et al., "Mechanisms in endocrinology: vitamin $\mathrm{D}$ as a potential contributor in endocrine health and disease," European Journal of Endocrinology, vol. 171, no. 3, pp. R101-R110, 2014.

[15] C. D. L. Marques, A. T. Dantas, T. S. Fragoso, and A. L. B. P. Duarte, "The importance of vitamin D levels in autoimmune diseases," Revista Brasileira de Reumatologia, vol. 50, no. 1, pp. 67-80, 2010.

[16] A. Antico, M. Tampoia, R. Tozzoli, and N. Bizzaro, "Can supplementation with vitamin $\mathrm{D}$ reduce the risk or modify the course of autoimmune diseases? A systematic review of the literature," Autoimmunity Reviews, vol. 12, no. 2, pp. 127-136, 2012.

[17] O. M. Çamurdan, E. Döğer, A. Bideci, N. Çelik, and P. Cinaz, "Vitamin D status in children with Hashimoto thyroiditis," Journal of Pediatric Endocrinology and Metabolism, vol. 25, no. 5-6, pp. 467-470, 2012.

[18] G. Tamer, S. Arik, I. Tamer, and D. Coksert, "Relative vitamin D insufficiency in Hashimoto's thyroiditis," Thyroid, vol. 21, no. 8, pp. 891-896, 2011.

[19] M. D. Lockshin, "Sex differences in autoimmune disease," Lupus, vol. 15, no. 11, pp. 753-756, 2006.

[20] P. Chagnon, S. Provost, C. Belisle, V. Bolduc, M. Gingras, and L. Busque, "Age-associated skewing of $\mathrm{X}$-inactivation ratios of blood cells in normal females: a candidate-gene analysis approach," Experimental Hematology, vol. 33, no. 10, pp. 12091214, 2005.

[21] M. Noguchi, H. Yi, H. M. Rosenblatt et al., "Interleukin-2 receptor $\gamma$ chain mutation results in X-linked severe combined immunodeficiency in humans," Cell, vol. 73, no. 1, pp. 147-157, 1993.

[22] G. Hernández-Molina, Y. Svyryd, J. Sánchez-Guerrero, and O. M. Mutchinick, "The role of the X-chromosome in immunity and autoimmunity," Autoimmunity Reviews, vol. 6, no. 4, pp. 218-222, 2007.

[23] Z. Özbalkan, S. Baǧişlar, S. Kiraz et al., "Skewed X-chromosome inactivation in blood cells of women with scleroderma," Arthritis and Rheumatism, vol. 52, no. 5, pp. 1564-1570, 2005.

[24] T. H. Brix, G. P. S. Knudsen, M. Kristiansen, K. O. Kyvik, K. H. Ørstavik, and L. Hegedüs, "High frequency of skewed xchromosome inactivation in females with autoimmune thyroid disease: a possible explanation for the female predisposition to thyroid autoimmunity," Journal of Clinical Endocrinology and Metabolism, vol. 90, no. 11, pp. 5949-5953, 2005.
[25] T. Ozcelik, E. Uz, C. B. Akyerli et al., "Evidence from autoimmune thyroiditis of skewed X-chromosome inactivation in female predisposition to autoimmunity," European Journal of Human Genetics, vol. 14, no. 6, pp. 791-797, 2006.

[26] X. Yin, R. Latif, Y. Tomer, and T. F. Davies, “Thyroid epigenetics: $\mathrm{X}$-chromosome inactivation in patients with autoimmune thyroid disease," Annals of the New York Academy of Sciences, vol. 1110, pp. 193-200, 2007.

[27] M. L. Melamed, E. D. Michos, W. Post et al., "25Hydroxyvitamin D levels and the risk of mortality in the general population," Archives of Internal Medicine, vol. 168, no. 15, pp. 1629-1637, 2008.

[28] K. Michaëlsson, J. A. Baron, G. Snellman et al., "Plasma vitamin $\mathrm{D}$ and mortality in older men: a community-based prospective cohort study," The American Journal of Clinical Nutrition, vol. 92, no. 4, pp. 841-848, 2010.

[29] D. Durup, H. L. Jørgensen, J. Christensen, P. Schwarz, A.-M. Heegaard, and B. Lind, "A reverse J-shaped association of allcause mortality with serum 25-hydroxyvitamin D in general practice: the CopD study," Journal of Clinical Endocrinology and Metabolism, vol. 97, no. 8, pp. 2644-2652, 2012.

[30] Q. Zhang, Z. Wang, M. Sun et al., "Association of high vitamin D status with low circulating thyroid-stimulating hormone independent of thyroid hormone levels in middle-aged and elderly males," International Journal of Endocrinology, vol. 2014, Article ID 631819, 6 pages, 2014. 


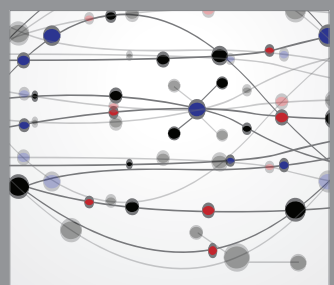

The Scientific World Journal
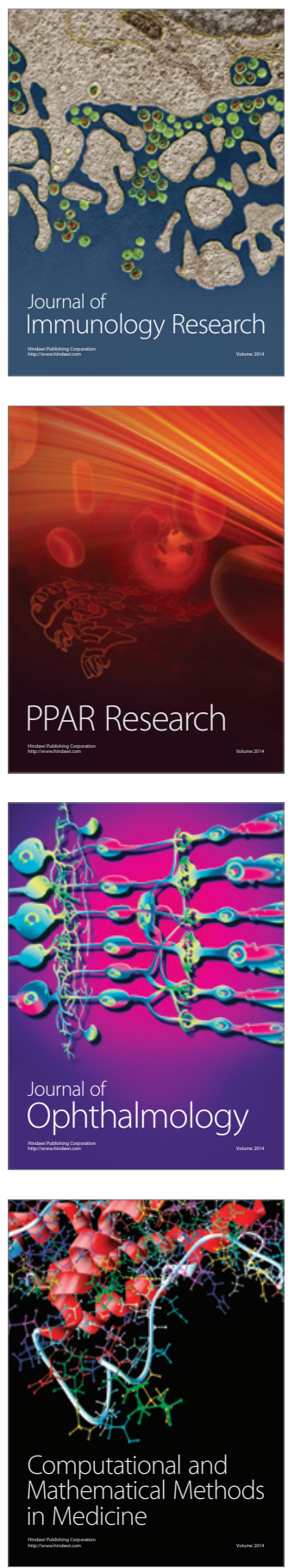

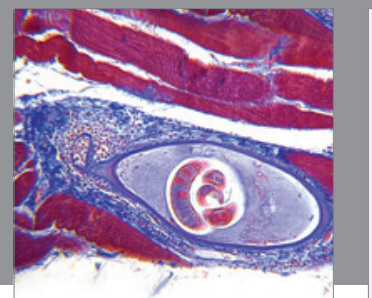

Gastroenterology

Research and Practice
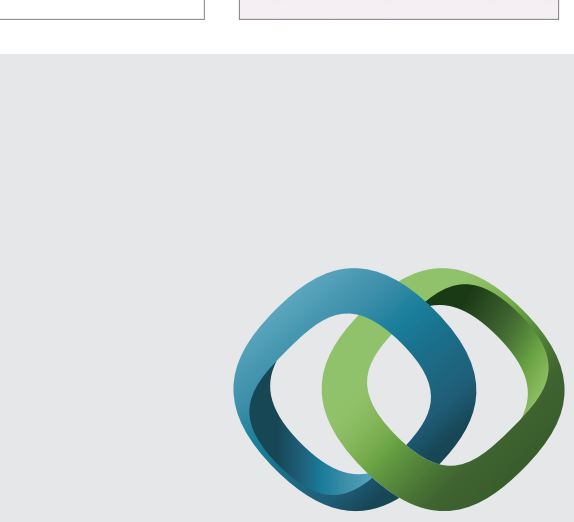

\section{Hindawi}

Submit your manuscripts at

http://www.hindawi.com
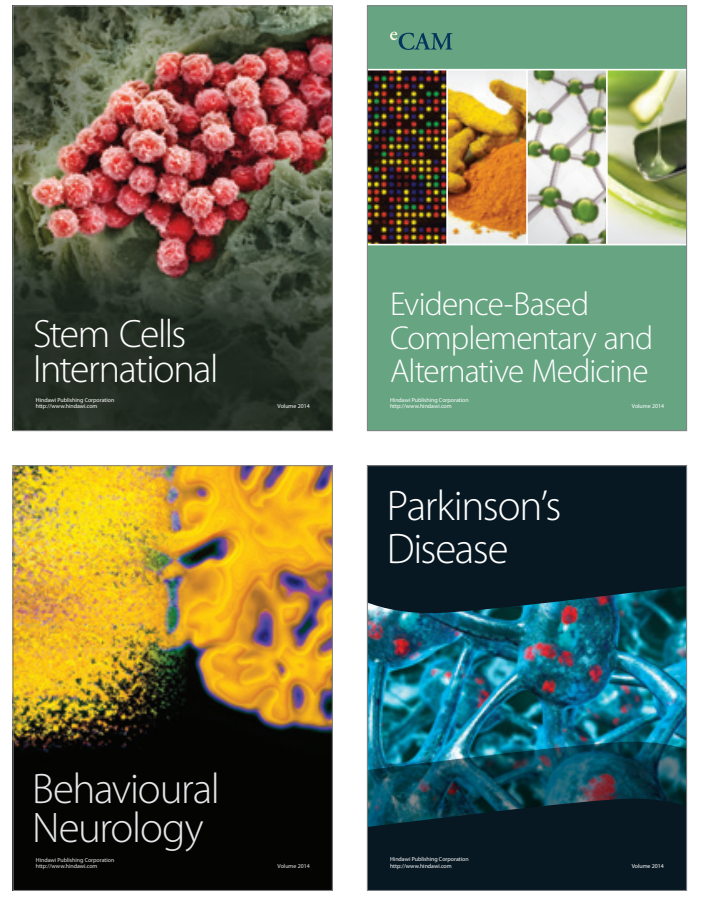
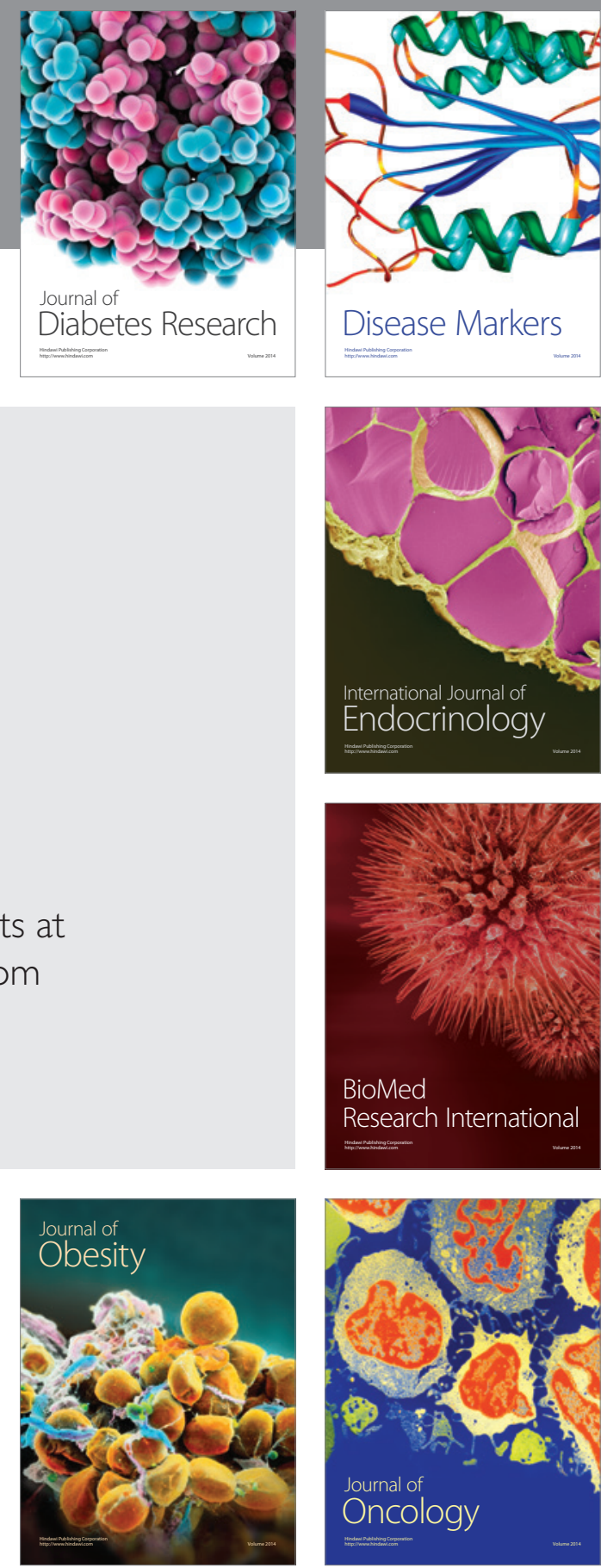

Disease Markers
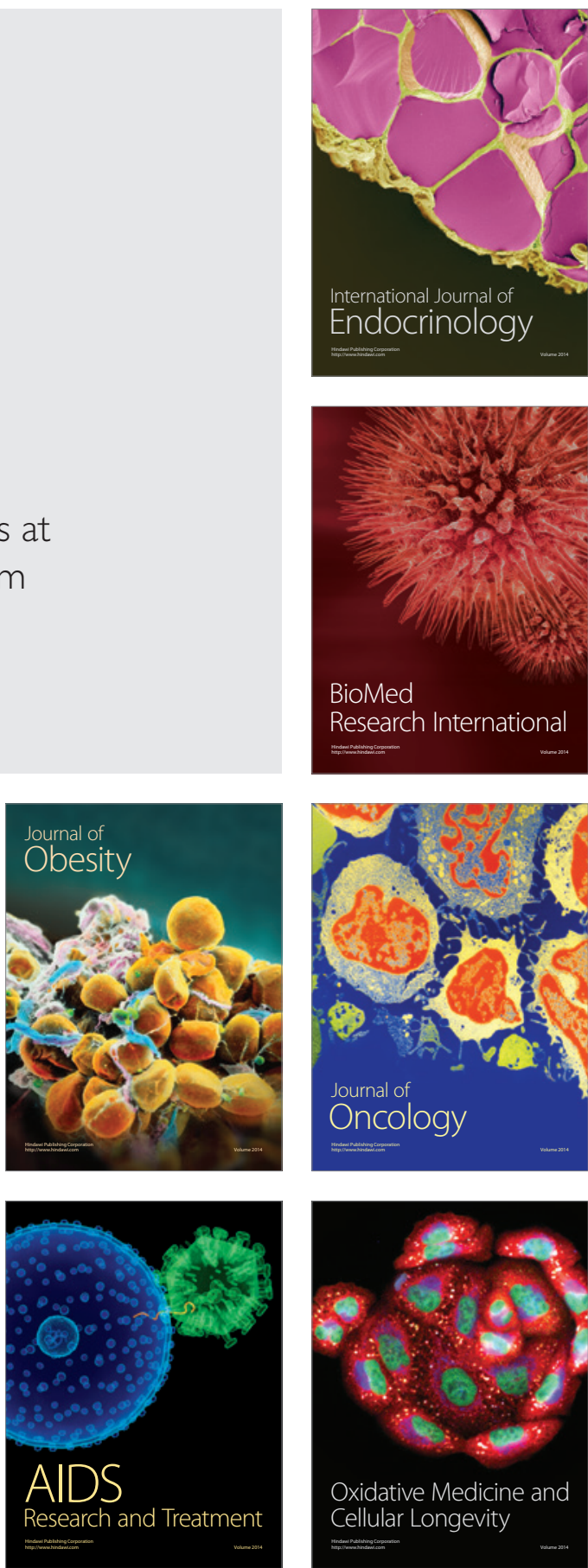